\title{
Representaciones y categorías de la violencia en el cine: un recorrido histórico y contextual
}

\section{Representations and categories of violence in the cinema; a historical and contextual journey}

Rafael Tonatiuh Ramírez Beltrán

rramirez@anahuac.mx

Centro de Investigación para la Comunicación Aplicada (CICA)

Universidad Anáhuac México

Av. Universidad Anáhuac núm. 46, Col. Lomas Anáhuac,

C.P. 52786, Huixquilucan, Estado de México

Editor: Rogelio del Prado Flores

\author{
Guardarme de la violencia, \\ y a se exprese mediante la lengua, \\ el puño o el corazón.
}

MARTIN LUTHER KING

\section{RESUMEN}

El artículo se aproxima a la violencia como elemento central en el cine del siglo XX y XXI, determinado históricamente por las condiciones sociales. Se trabaja sobre las formas de representación social, siguiendo la relación de los sujetos consigo mismos y la naturaleza. Está relación se observa críticamente, como construcción social y práctica discursiva, dado la importancia del cine y sus implicaciones con la violencia; se reconoce que el ingrediente de la violencia en el arte cinematográfico se ha manifestado de múltiples formas y a lo largo de la historia.

De igual forma se sistematizan algunas de las diferentes aristas presentes en las diversas tramas que a lo largo de más de cien años del arte cinematográfico trabajando sobre producciones de distintas partes del mundo. Se detiene a problematizar con ejemplos cinematográficos de variadas cinematografías, cómo el ingrediente de violencia de muy diversos grados, formas, matices y niveles es omnipresente en el hecho cinematográfico. El cine sin violencia es más excepción que regla. Lo que no resulta un asunto menor, dadas las repercusiones sociales y éticas de los diversos films en la realidad social. Por lo anterior el capítulo se restringe y limita a analizar cuatro categorías específicas: a) La Acción/violencia visto como género cinematográfico, particularmente la evolución reciente 
del cine bélico, en las últimas dos décadas y sus reminiscencias y diversos tratamientos y manifestaciones en las cinematografías principalmente la alemana y norteamericana. Nos interesa aquí ver el tratamiento de la violencia en el cine posterior a la caída al muro de Berlín; b) La violencia intrafamiliar en el cine, sobre todo a partir de los años noventa del siglo pasado y con la irrupción internacional de los derechos humanos (infantiles, derechos de la mujer, ambiente sano, etc.) el análisis se centra en películas españolas, inglesas y norteamericanas, también de las últimas veinte años; c) Instituciones sociales y violencia, ejemplos en el cine y la violencia en cárceles, hospitales y escuelas y; d) la violencia sobre los recursos naturales: la violencia como razón de acumulación y no de sustentabilidad en los documentales ambientales. Se avanza en algunas reflexiones finales que integran los seis asuntos tratados.

Palabras clave: representación social en el cine, violencia en el cine, sociedad y violencia

\begin{abstract}
The article approaches violence as a central element in 20 th and 2I st century cinema, determined historically by social conditions. We work on the forms of social representation, following the relationship of the subjects with themselves and nature. This relationship is observed critically, as a social construction and discursive practice, given the importance of cinema and its implications with violence; it is recognized that the ingredient of violence in cinematographic art has manifested itself in multiple forms and throughout history.

In the same way, some of the different edges present in the different plots that over more than one hundred years of the cinematographic art working on productions from different parts of the world are systematized. It stops to problematize with cinematographic examples of varied cinematographies, how the ingredient of violence of very diverse degrees, forms, nuances and levels is omnipresent in the cinematographic fact. Cinema without violence is more exception than rule. Which is not a minor issue, given the social and ethical impact of the various films in the social reality. Therefore, the chapter is restricted and limited to analyzing four specific categories: a) Action / violence seen as a cinematographic genre, particularly the recent evolution of war movies, in the last two decades and its reminiscences and various treatments and manifestations in cinematographies mainly German and North American. We are interested in seeing the treatment of violence in cinema after the fall to the Berlin Wall; b) Domestic violence in the cinema, especially since the nineties of the last century and with the international breakthrough of human rights (children, women's rights, healthy environment, etc.) the analysis focuses on Spanish films, English and North American, also of the last twenty years; c) Social
\end{abstract}


institutions and violence, examples in the cinema and violence in prisons, hospitals and schools and; d) violence over natural resources: violence as a reason for accumulation and not for sustainability in environmental documentaries. Progress is made in some final reflections that integrate the six issues discussed.

Keywords: social representation in the cinema, violence in the cinema, society and violence

\section{INTRODUCCIÓN}

El cine es el arte que mayor influencia tiene, en la actualidad, sobre nuestra sociedad (Solorzano, 20I9). Visitarlo, entretenerse y divertirse en el cine es y ha sido por largo tiempo una sana costumbre de los más de doscientos países del mundo. Pero el arte cinematográfico tiente también repercusiones, económicas, políticas, educativas, culturales e ideológicas, por lo que es indispensable su análisis.

Son muchos los géneros e incontables las tramas y contenidos que se desarrollan, año con año, en las diferentes industrias cinematográficas. En este artículo nos focalizaremos al cine y su relación con la violencia. Cada país ha aportado elementos cruciales de su propia historia a la cinematografía, en donde inevitablemente está presente — como dijera Marxesa gran partera que es la violencia social.

El cine y la violencia, como se puede constatar en los ejemplos referidos, tienen una relación permanente. Parece ser un tipo de cine atemporal y mundial con una carga de violencia irremediable. En los siguientes apartados veremos que en el cine la representación de la violencia es múltiple. Como queda claro pensamos que son muchas las aristas a explorar.

Citamos dos categorías de películas que distinguimos hasta el momento en las que el cine es: i) explícitamente violento (crímenes, daño físico, actos contra la voluntad del individuo, etc.) y 2) implícitamente violento (daño psicológico, amenazas, persuasiones, suspenso como precedente a un daño, etcétera).

En el cine, en general, el combustible que dinamiza las historias es con frecuencia el conflicto o problema y este con recurrencia presenta su cara de enfrentamiento, muchas veces como violencia física o psicológica. No es fácil distinguir si el cine ha documentado sistemáticamente la violencia mundial o el cine es otro ingrediente social — junto con otros medios - potenciador de la violencia. Esta polémica con frecuencia se muerde la cola como víbora sin llegar muy lejos: todavía no hay una conclusión definitiva al respecto en la literatura disponible.

Por lo anterior hemos elegido, para este artículo, acotar a cuatro de sus manifestaciones violentas en el cine, estas son: la violencia como cine de acción, la violencia intrafamiliar, la 
violencia en su cara institucional y simbólica o tangible y algunos ejemplos de documentales que dan cuenta de la violencia sobre los recursos naturales. Solo mencionaremos ejemplos de las últimas dos décadas, pero nos hemos esforzado en que sean cinematografías representativas de diversas partes del mundo.

\section{VELANDO ARMAS Y DEVELANDO LOS TIEMPOS DEL CINE}

La violencia es inevitable e injustificable.

En este apartado mostraremos cuál es el largo trayecto del cine y la violencia. Compartiremos algunos elementos y ejemplos en un contexto histórico que ha sometido al cine, prácticamente desde su nacimiento a finales del siglo XIX hasta la actualidad, a recuperar la fuerza contra los otros como algo siempre presente en sus tramas y narrativas.

No es menor ni en tamaño la repercusión, trascendencia o dimensión de la relación entre el cine y la violencia. Si la miramos críticamente, como construcción social y práctica discursiva, dado que el siglo XX es simultáneamente el siglo del cine (por su desarrollo e impacto) y —lamentablemente - también el de la guerra (mundiales, civiles, locales etc.) y la violencia sin límite ya desbocada; teniendo que reconocer que este vínculo del arte cinematográfico se ha manifestado de múltiples formas.

Esta característica del siglo XX como el más violento se precipitó en las últimas décadas del mismo y por inercia en el principio del actual dinamizándose con los ataques del i i de septiembre de 200 I en Estados Unidos y la vigorosa y cuestionable reacción posterior por parte de los gobiernos norteamericanos, ya en este siglo, y sus intervenciones militares en el Medio Oriente.

La violencia es un producto histórico. Cada época asume, de acuerdo con su determinación histórica, a la violencia y la justifica de acuerdo con la ambición, los elementos en conflicto, la conformación de bandos o intereses, los miedos y su implementación de acuerdo con el desarrollo tecnológico. Hay una cantidad importante de formas de violencia (económica, laboral, física, psicológica, simbólica, ambiental, etc.), pero es el momento social en que sucede, el que la hace específica y peculiar. No hay sociedad sin características violentas.

Basta ver el contexto de los conflictos militares en todo el mundo en la última era: tenemos como civilización más de setenta años viviendo en medio de una guerra planetaria, que no cesa y que ha tenido diferentes nombres: Segunda Guerra Mundial, Corea, Vietnam, Árabe-Israelí, Camboya, Fría, Centroamérica, Tormenta del Desierto, Afganistán, Irak, 
neoliberalismo vs. humanidad, Siria, Ucrania, y las muertes de fenómenos sociales como la migración, el narcotráfico y el terrorismo, etc. Sería muy largo citar los conflictos entre naciones, internos de los estados y regionales que han sido muchos y de muy diversa intensidad. Esto ha generado una cultura de la guerra y la muerte. Una sociedad del dolor y el sufrimiento. Una civilización dominada por la sinrazón violenta que ha llegado a extremos de convertir a las armas en instrumentos económicos con un valor superior al de la especie humana. Un solo dato ilustra lo anterior: en I, 4 billones de dólares al año se estima es el gasto anual mundial militar de los Estados Unidos ${ }^{\mathrm{I}}$ que, si fuese invertido en atacar la pobreza, la marginación, la inequidad, y en generar mínimos de bienestar como educación, salud, ambiente adecuado, agua potable y vivienda, muchos de los conflictos armados podrían reducirse.

La vida sigue siendo más barata que la muerte, como sostenía el Premio Nobel de Literatura colombiano, Gabriel García Márquez (El cataclismo de Damocles: 1986) hace ya casi tres décadas, pero eso parece a nadie importar en un contexto que ha puesto a la rentabilidad y al mercado en el corazón del planeta. Las armas son un gran negocio que suele abaratar la vida (Benítez, Meixueiro, Ramírez, 20II).

Conceptualmente, Jiménez (20II) ha dividido a la violencia en dos grandes grupos de los que el cine ha tomado/reconstruido/trasmitido sus representaciones, a saber:

Una primera idea de violencia, en un sentido amplio, se refiere al daño ejercido sobre los seres humanos por parte de otros seres humanos. Una segunda idea de violencia es el resultado de la interacción entre la agresividad natural y la cultura. Es decir, violencia es cualquier acción (o inacción) realizada a otro ser humano con la finalidad de causarle daño físico o de otro tipo, sin que haya beneficio para la eficacia biológica propia. Lo que caracteriza a la violencia es su gratuidad biológica y su intencionalidad psicológica.

Asimismo, y solo para referir como ejemplo de cómo el cine no ha sido ajeno a estas dos culturas, pongamos las luces sobre el cine bélico. Si sólo tomáramos como variable a los niños en contextos bélicos o poco propicios para su desarrollo, referimos algunas películas en las que se manifestaba esta relación. Son películas algunas desconsoladoras producidas en las últimas décadas, en las que encontramos el daño intencionalmente a otros seres humanos y un contexto que la determina, por ejemplo, en cintas como:

Trenes rigurosamente vigilados (Menzel, 1996: Checoslovaquia), Adiós a los niños (Malle, 1987: Francia), Malena (Tornatore, 2000: Italia), El imperio del sol (Spielberg, 1987: Estados

I Los gastos militares han tenido un crecimiento vertiginoso en los últimos 70 años. Antes de la Segunda Guerra Mundial estos gastos en todo el mundo se estimaron en unos 48 mil millones de dólares, pero ya en 1972 habían crecido a 240 mil millones [I] y llegaron a I,4 billones de dólares en I990[2] (Sivard, 20I0). 
Unidos), Ven y mira (Klimov, 1986: URSs). O los excelentes documentales Los niños de Morelia (Villaseñor, 2004: México), En los brazos de extraños (Harris, 2000: Estados Unidos), o el film chileno Machuca (Wood, 2004: Chile-España), la multipremiada Vivir al límite/ The Hurt Locker (Bigelow, 2009: Estados Unidos), Promesas (Goldberg y Bolado, 200I: Estados Unidos), La guerra (Avnet, 1994: Estados Unidos), Bienvenidos a Sarajevo (Winterbottoma, 1997: Reino Unido), La lengua de las mariposas (Cuerda, 1999: España), El círculo perfecto (Kenovic, 1997: Bosnia-Francia), Voces Inocentes en la que Mandoki relata la guerra en la República del Salvador de I980 (México, 2004), Una señal de esperanza (Kassovitz, 1999: Bosnia-Francia), y Lastortugas pueden volar (Ghobadi, 2004:Irak), o la premiada en Cannes Los Caballos de Dios (Nabil Ayouch, 2012: Marruecos), inspirada libremente de los actos terroristas del I6 de mayo en la ciudad de Casablanca o la niña que es salvada de la violencia en Un asunto de familia (Japón, 2018), o el niño sobreviviente a la devastación de una sociedad Cafarnaum (Líbano, 20I8).

A esta lista le podríamos añadir una innumerable cantidad de films incluso por temas o conflictos particulares. Por ejemplo, sobre la Segunda Guerra Mundial: El puente sobre el río Krwai de David Lean (1957), Patton, de Franklin J. Schaffner (1970). La película 194I, Steven Spielberg (1979); El imperio del sol del mismo Steven Spielberg (1984); Bastardos sin gloria de Quentin Tarantino (2007); y la recientes La ladrona de libros, de Brian Percival (2013), Inquebrantable, dirigida por Angelina Jolie (2014), Bajola Arena, de Martin Zandvlie (2016). $\mathrm{O}$ incluso incluir aquí toda la larga saga de películas que dan cuenta, dentro de esta guerra mundial, del proceso de exterminio de los judíos en los campos de concentración nazis, tal vez la lista alcance centenas.

Otro ejemplo particular, también se podrían referir las películas sobre la guerra de Vietnam y dar matices sobre el tratamiento de la violencia, antes, durante y después del acontecimiento militar. Todavía sin selección mencionaríamos para este caso: Regreso sin gloria, Hal Ashby (1978); Elfrancotirador, Michael Cimino (1978); Apocalipsis Now, Francis Ford Coppola (1979); El tríptico de Oliver Stone: Pelotón (1986); Nacido el 4 de julio (1989); Entre el Cielo y la Tierra (1993); Good Morning Vietnam, Levison (1987); Cara de Guerra, Kubrick (1987); Pecados de Guerra, Brian de Palma (1989); hasta la parte más importante del film Forrest Gump, Zemeckis (1994); Fuimos Héroes, Randall Wallace (2002); o Los obscuros objetos del Pentágono, Steven Spielberg (2017).

Como se observa son varios los caminos que se pueden tomar para hablar del cine y las acciones de violencia y daño humano. Para un artículo posterior nos interesa destacar las particularidades de violencia en cine reciente mexicano del 2000 al 2013, es decir de Amores Perros (González, 2000: México) a Heli (Escalante, 20I3: México) y La faula de Oro (Quemada-Díez, 20I3: México-España-Guatemala). Películas como Nicotina (Rodríguez, 2003: 
México), El Violín (Vargas, 2007: México), El Laberinto del Fauno (Del Toro, 2007: México), Días de Gracia (Gout, 20Ir: México), El Infierno (Estrada, México: 2010), Después de Lucía (Franco, 2012: México), o La otra parte, la bistoria no contada del narco (Colorado, 20I8) darán pauta para analizar asuntos como el mal, la delincuencia e ilegalidad, los peligros de los migrantes, el bullying o el narcotráfico.

Otra posibilidad sería indagar, por ejemplo, en el cine referido a la Revolución mexicana que también es muy amplio en géneros, tiempos, temáticas y asuntos relacionados con la violencia. Bastaría citar la cinematografía de Fernando de Fuentes - El prisionero trece (1933), El Compadre Mendoza (1934) y Vámonos con Pancbo Villa! (1936) — para caer seducido por tiempo indefinido entre novelas, temas, ametralladoras y balas.

\section{LA VIOLENCIA COMO GÉNERO CINEMATOGRÁFICO DE ACCIÓN}

Los conflictos socioeconómicos, las guerras localizadas, la delincuencia misma, con sus desigualdades e injusticias estimula la violencia. Estamos viviendo una época de crueldad y terror irracionales encarnados en la violencia moraly física: guerras, crímenes, persecuciones nos envuelven como becbos cotidianos.

GABRIEL CAREAGA

El cine a lo largo de sus más de cien años de historia mundial y con fines de comercialización, programación, selección, documentación, investigación, apreciación y clasificación se ha dividido en géneros cinematográficos. Estos presentan características especiales en cuanto a su forma, narrativa, descripción, tratamiento, tipos de personajes, arquetipos, tramas, escenarios, iluminación o ambientes, contextos históricos por las temáticas, tomas fotográficas más usadas o recurrentes, situaciones o formas de comportamiento de los personajes, así como características comunes y general en las que se puede englobar, clasificar o determinar un film.

Los géneros cinematográficos son muchos y casi cada uno de ellos pude subdividirse por particularidades o evolución cinematográfica. A pesar de ello y sólo para dar marco al presente apartado podemos reconocer los siguientes géneros, casi en orden de aparición en la historia del cine: documental, biográfico, histórico, musical, comedia, infantil, western, aventura y acción, bélico, ciencia ficción, drama, suspenso, negro, terror/horror, erótico.

De los anteriores géneros son cuatro los que podríamos reconocer como más violentos, a saber: a) el cine bélico, cuenta hazañas de guerra históricas documentadas o de ficción, 
en las que el campo de batalla se hace indispensable junto con armas, intereses, estrategias, motivos, disputas, enfrentamientos políticos y militares. Generalidades de él dimos en el apartado anterior; b) el de aventuras o acción: es en el que con mayor legitimidad se ejerce la libertad de los recursos violentos, los elementos que juegan son: un héroe, un villano, una joven bella y en problemas, actores secundarios de soporte a la trama, la narración llena de persecuciones, efectos especiales, explosiones, sangre, espectacularidad, y casi siempre un final feliz y romántico. Son las obras que el cineasta francés Jean-Luc Godard refería como cine de pistola y mujer; venganzas, disparos, muertos y mal heridos inevitablemente ${ }^{2}$. Tal vez el que se produce en mayor número de películas y financiamiento-costo (junto con la comedia) en Hollywood, de ahí uno de sus poderes persuasivos; c) suspenso, narraciones en las que el film, a partir de una situación problemática, va dando giros dotando de información al espectador que lo anticipan sobre los peligros siempre al acecho de los protagonistas. Daremos cuenta de este cine con de film de violencia interfamiliar; y d) El documental como la narración que trata de aproximarse con el cine a situaciones antropológicas, históricas, tecnológicas o naturales/ambientales para tratarlas en forma objetiva, descriptiva y casi siempre compleja y que obligan al realizador y/o al espectador a tomar una posición. Nos interesan ejemplos de documentales sobre las causas y los efectos violentos sobre la violencia, también legitimada, que le hacemos a la naturaleza.

Algunos de estas categorías y elementos se tratarán a continuación. El método fue buscar algunas con estos rasgos dentro de las categorías como ejemplos cinematográficos, sin que sean exhaustivos, que ejemplificaran las formas de violencia.

\section{LA VIOLENCIA INTRAFAMILIAR EN EL CINE}

La belleza ba desertado de las pantallas. BRIAN DE PALMA

Por violencia intrafamiliar hay consenso en entenderla como la que sucede al interior de la familia y que incluye a los habitantes de un mismo domicilio — no necesariamente con lazos sanguíneos-, que va en el caso extremo de la violación a los tipos de maltrato psicológico, físico, moral y sexual.

2 Realizadores como Quentin Tarantino se han instalado cómodamente en este cine forzando y desbordando otros géneros. Por más de veinte años (de Perros de reserva, 1992, a Django, 20I2), Tarantino se ha vuelto un director cinematográfico de culto, para una inmensa cantidad de jóvenes e incluso generaciones, sobre todo por el exceso de recursos cinematográficos violentos más que por sus aportes artísticos reales. 
Pretendemos documentar que la violación está presente a nivel microfísico (familiar) y que se da muchas veces como una estrategia de dominación en las diferentes relaciones que se dan al interior de la familia, no solamente de los padres (madre, padre o ambos) hacia los hijos, sino también de hijos a padres, de hermanos a hermanos, de esposo a cónyuge, o de algún miembro a la sociedad en su conjunto. Nos asomaremos a las tramas y a las situaciones de fuerza psicológica y física.

\section{I Violencia del hombre a la mujer: Te doy mis ojos}

En Te doy mis ojos (Bollain, I., 2003: España), Pilar huye del departamento en una noche con su pequeño hijo para buscar refugio con su hermana en Toledo. Ella está apunto de contraer nupcias con un joven escoces y pronto se dará cuenta de que su hermana huye de Antonio, el esposo de Pilar, que inconteniblemente casi siempre por celos, la termina golpeando o vejando. Lo interesante de la película es que después de esta huida, Pilar regresa a su hogar ante la promesa de Antonio de que eso no pasara más. Sin embargo, ya está metida en un ciclo del cual Antonio no puede salir. Aun con ayuda psicológica y terapia de grupo nada parece contener a Antonio y la furia se desata cuándo Pilar decide trabajar.

La película denuncia un hecho terriblemente atroz, pero lamentablemente presente en la realidad mundial. Tal vez sea esta forma de violencia del esposo hacia su cónyuge la más común. Algunos cálculos de la Organización Mundial de la Salud sostienen que el 30\% de las mujeres que han tenido una relación de pareja refieren haber sufrido alguna forma de violencia física o sexual por parte de su pareja. Otro dato igual de grave es que es que $38 \%$ de los asesinatos de mujeres que se producen en el mundo son cometidos por su pareja.

\subsection{Violencia entre hermanas: Malena es nombre de tango}

Otra forma de violencia es la que se da entre hermanos. Un ejemplo de lo anterior es la a historia de Malena y su hermana melliza Reyna. La película Malena es nombre de tango (Herrero, I996: España-Francia-Alemania) inicia con Malena suplicando a Dios que la vuelva niño, ¿tiene esa pequeña problemas de identidad femenina? No. Tiene una rival en casa que es mejor que ella: toca el piano impecablemente, es más bella, y está ajustada de mejor forma a los requerimientos de la mamá. Malena no quiere o no puede competir. Asumirá la incompetencia retirándose.

La omnipresencia de la hermana como factor determinante no quedará claro sino hasta el final: es Reyna la que quiso ser como Malena. Ella sí quiso competir y ganar, por lo que se opondrá y violentará la vida de la hermana. 
En la vida los hermanos pueden ser muchas cosas: ejemplo, reto, amor, enseñanza, guía, dolor, sorpresa, esperanza, espejos cóncavos, convexos y planos donde nos miramos. Es la demostración fehaciente y cercana de que la percepción es infinita en el ser humano. De que una misma educación, dirigida a dos personas, nunca será la misma, así vengan del mismo vientre, nazcan con diferencia de minutos y compartan la vida durante largas horas. Saberse hermano es siempre paradójico: ser igual y diferente a un tiempo. Próximo y lejano. Idéntico y opuesto. Amigos y rivales.

\subsection{Violencia del padrastro a hijo: El silencio de Oliver}

La cinta comienza con una desesperada carrera del niño Oliver, el rostro sangrante y el aliento agitado se convierten en el leitmotiv de esta cinta. Oliver es un niño de nueve años, vive con su madre y Frank, su nueva pareja a quien se ha unido luego de la separación de su esposo, quien es homosexual.

Cada vez que el niño es golpeado acude a su padre y no a su madre, como pareciera más lógico. Motivado por las inverosímiles explicaciones de Oliver, el padre comenzará a indagar sobre el maltrato, ante la negativa de Oliver para confesar el nombre del culpable. Al descubrir que es el padrastro, buscará, por medio de un juicio, recuperar al niño para que viva con él.

El silencio de Oliver (Pope, 1997: Gran Bretaña) es un drama que se sustenta en el infinito e impensable debate sobre los valores actuales: el derecho a la paternidad, las formas de educar, el rol de los padres ante los hijos de matrimonios anteriores.

El cuarto donde duerme Oliver, en la casa de su madre, le sirve como refugio ante el enemigo próximo. Es una suerte de panóptico, en el que el niño observa y se salvaguarda del peligro. A través de las persianas o mediante un cochecito a control remoto al que le ha adaptado un espejo, vigilará los movimientos del padrastro temido y violento. Frank, con el pretexto de educarlo, lo agrede por nimiedades como rayar un mueble o tomar jugo directamente del envase (como lo hace su padre natural). El verdugo tiene el buen cuidado de señalar límites cuando están a solas. La justificación a la pedagogía del puño y la nariz sangrante. El padre del niño tratará de persuadir a su exesposa de que su nueva pareja es el autor de las golpizas que recibe el pequeño Oliver. Ella no le cree o no le quiere creer.

Cuando por fin lo constata, trata de remediarlo echándolo de su casa; pero el padrastro regresa, llora y se defiende, argumentando que así lo educaron, que él no está mal, que es el muchacho el que no lo acepta. La madre cederá porque es más fuerte el amor que le tiene a la pareja y porque teme un nuevo fracaso. Esta situación de ambivalencia parece ser una constante en este tipo de cine. 
También la película pone a debate el viejo tema del padre postizo y golpeador, pero revivido con la emergencia de nuevas identidades: la figura de la madre ausente por el trabajo que desempeña, el padre no heterosexual y el impacto en los hijos por la disolución del primer matrimonio.

\subsection{Violencia del hijo a la familia: Tenemos que bablar de Kevin}

En Tenemos que bablar de Kevin (Ramsay, 20ır: Reino Unido-Estados Unidos), narrado en una larga serie de flasbback, vemos el último grado de violencia intrafamiliar: un adolescente contra la madre/hermana/padre/sociedad. Desde pequeño, Kevin da muestra de inadaptación y respuestas violentas a una madre primeriza que no sabe cómo reaccionar, sin ninguna credibilidad por parte de su padre. Conforme Kevin va creciendo los rasgos violentos se desbocarán al poseer un arco y una flecha. Kevin acabará con los familiares y compañeros de escuela, quedando viva la madre, que sufrirá otra forma de violencia del vecindario.

En Tenemos que bablar de Kevin presenciamos desde el nacimiento de Kevin, su desarrollo físico e intelectual, hasta el padecimiento social de la madre, posterior al asesinato colectivo que va de la escuela a la casa perpetrado por este sicópata adolescente. La sociedad culpa a la madre de los hechos trágicos que narra esta ficción. La madre es la única sobreviviente de la familia. Las preguntas sobre la violencia, sus causas y efectos sociales surgen: ¿Esta señora hasta dónde es culpable de un niño con inteligencia sorprendente para el mal?, ¿qué se podría haber hecho?

Después de ver esta película — sobre todo en ámbitos escolares — hemos tratado de evitar hablar del síndrome de Kevin, tal vez tratando de exorcizarlo con el silencio. Sin embargo, ante los hechos actuales de acoso escolar de todo tipo incrementándose, consideramos que lamentablemente no lo estamos logrando como sociedad. Los Kevin comienzan a ser numerosos.

\subsection{El niño bonito o la venganza contra la sociedad individualista}

La película Beautiful Boy (Shawn Ku, 20ıо: Estados Unidos) va más lejos en el dolor de los padres ante hijos que se les escapan de las manos en la época actual. En este film tenemos una familia de clase media norteamericana actual, compuesta por Bill, Kate y el hijo que recientemente ha ingresado a la universidad, Sammy. El padre trabaja en una oficina de negocios y ella por su cuenta corrigiendo el estilo de noveles escritores. Viven juntos en una hermosa casa en donde todo, en apariencia, parece funcionar; pero más allá de la superficie, no es así. 
En principio, la pareja no es feliz: no duermen juntos, no comparten otros espacios, comen solos y preparan con desgano unas próximas vacaciones. Sammy, que es lo único que los ha hecho permanecer juntos hasta ahora, se irá lejos de ellos, en su primer semestre de estudios superiores.

Por su parte, Sammy tampoco es feliz. Lee cuentos escritos por él, ante auditorios universitarios de egoístas, aburridos y evadidos estudiantes. Sammy se nota deprimido en este momento de su vida, pero nadie le presta mayor atención.

La única forma de contacto familiar es una llamada telefónica — una noche antes de la tragedia- en la que coinciden los tres miembros en los respectivos auriculares, en la que terminan de planear las vacaciones a Miami. La coincidencia dura solo unos segundos. Sammy casi llora, pero se reprime y la madre lo instruye, el padre cuelga. Luego vendrá el asesinato colectivo de compañeros de escuela y el suicidio.

El foco ahora son los atormentados padres. Aquí comienza otra película en la que dos seres humanos infelices tienen que cargar una culpa sobre el vacío de su existencia, sobre lo que creyeron que era el sentido de su mínima existencia se les revierte. La escasa felicidad que les proveía el hijo, primero se vuelve negación y posteriormente odio, persecución, señalamiento, suplicio mediático, alejamiento, ocultamiento, pena y exclusión. En la película Beautiful Boy late todo el tiempo la incógnita sobre quién crea a los delincuentes: ¿La familia y los padres, de por sí infelices e individualistas por el desarrollo de traumas infantiles por las ausencias o sobrecuidados?; ¿ ¿los medios de comunicación que luego usan estos hechos para subir el rating?; ¿los videojuegos de los que hay decenas de palancas en la recámara de Sammy?; ¿ ¿la ausencia de amigos?; ¿la inoperancia de las instituciones para encausar las motivaciones individuales?; ‘ iel miedo?, o una sociedad en su conjunto, que en suma, se admira de lo mismo que crea, como estos niños hermosos convertidos en monstruos con armas disponibles.

\section{CINE DE INSTITUCIONES SOCIALES Y VIOLENCIA}

En este apartado se ejemplifica con películas que están documentando lo que pasa al interior de las instituciones, ejemplos de cárceles, hospitales y escuelas. Tenemos que reconocer que aquí los ejemplos son todavía más acotados. Es fácil entender que todo esfuerzo en compendiar las instituciones carcelarias, hospitalarias y escolares en el cine será en vano. Por ser instituciones sociales para resolver problemas de educación, enfermedad o rehabilitación su presencia cinematográfica es inmensa. Como lo son también las formas de violencia y los sofisticados y bastos dispositivos disciplinarios a su interior. 


\section{I La violencia es una enfermedad mental en Atrapado sin salida}

En el clásico filme sobre instituciones psiquiátricas Atrapado si salida (Forman, 1975: Estados Unidos) se sigue a McMurphy desde su ingreso al psiquiátrico, que elige para evadir la prisión. Él es una persona normal (e incluso hábil e inteligente) enfrentado a una muy rígida institución de salud mental. Los pacientes tienen una rutina que cumplen: hora de dormir, desayunar, terapia grupal, tomar medicina, jugar basquetbol, ver televisión, etc. Son enfermos mentales que son tratados como máquinas. Esta cotidianidad se altera con la llegada de McMurphy.

Él, desde su ingreso, desafiará el orden establecido, demostrando que éste no es el mejor espacio de los mundos posibles. Hará evidente que son las instituciones las que están enfermas del mismo modo que enferman lo que tocan y no tienen un interés genuino en curar. McMurphy no es un militante de la antipsiquiatría, es un hombre que la quiere pasar bien y si eso beneficia a los demás, mejor todavía. Pero esto en las instituciones totales es tomado como insubordinación.

La subversión de este personaje en la cinta es sometida por un dispositivo/estrategia desde el poder: una enfermera es la herramienta en este caso. Una mujer impecable e implacable en la aplicación. Su objetivo: volver todo a la anormalidad cotidiana. Lo que incluye a McMurphy, quien con descargas eléctricas al cerebro será convertido en otro miembro de la institución para su posterior extinción.

\subsection{La violencia no se cura con la violencia: Los bijos de la calle}

En Los bijos de la calle (Barry Levinson, I996: Estados Unidos) se narra cómo por un asalto y la posterior destrucción de un carrito de bot dogs, así como por un crimen involuntario, sin duda violento, una pandilla de niños neoyorquinos es sentenciada a ir a un reformatorio. Ahí son víctimas de todo tipo de violencia por parte de los celadores. Al salir, pasando un tiempo, podrán vengarse de los hombres que abusaron de ellos en forma legal y física demostrando que la rehabilitación jamás se logrará con actos abusivos.

El título original de este film es Sleepers que es un término que se emplea -explica la película- en el caló del Bronx para designar a los niños que pasan alguna temporada en la correccional, esto según interpretamos es debido a dos razones por lo menos: los pequeños infractores están como dormidos, olvidados, inactivos, fuera de acción; pero también la metáfora puede llevarnos hasta el límite. Son los durmientes de los rieles por los que pasa todo y también todo deben soportar sin alternativa.

Los cuatro niños sufrirán la cárcel con todo lo inmisericorde que pueden ser esos claustros poco humanos. Al egresar, dos ellos se volverán, ahora sí, unos crueles y despiadados 
asesinos que sin remedio continuarán hasta que la fatalidad los detenga para siempre. Otro buscará en el derecho una forma de revancha personal, solo uno alcanzará la normalidad no sin traumas y frustraciones. Los bijos de la calle vuelve a traer a cuentas debates inconclusos como los derechos de los niños, la reclusión de menores, los niños de la calle y la necesidad de la familia como principio o fin de la sociedad.

\section{$5 \cdot 3 \mathrm{El}$ profesor ante la mentira infantil y un periplo comunitario violento o La caza}

En la película La caza (Vinterberg, 20I2: Dinamarca), el profesor de preescolar Lucas tiene que pasar un largo proceso y periplo, del cielo al infierno, cuando un comentario de la pequeña alumna Klara — menor de seis años de edad— ante la directora de la escuela de párvulos, es escuchado, decodificado, desvirtuado, resignificado, sesgado, deformado, expuesto, socializado, creído y perseguido incluso judicialmente.

Lucas es un profesor que, al parecer, ya tuvo una experiencia en su labor como docente en un nivel superior, pero que al cerrar el colegio tiene que incorporarse a uno de preescolar; esta circunstancia profesional parece no preocuparle mayormente. Lucas es un profesor que disfruta lo que hace y es comprometido: juega casi siempre con los niños, se manifiesta también cuando lucha o juega a perseguirlos por el gran patio escolar, se queda más allá del horario escolar.

El profesor Lucas pasa por una circunstancia de transición en su vida; está recién divorciado y libra una batalla para poder pasar más tiempo con su hijo adolescente llamado Marcus. Inicia una relación afectiva con una extranjera que trabaja en el mismo jardín de niños en el que labora. Pero esta transición jamás se hace presente en su práctica docente.

En la película $L a$ caza observamos el crecimiento de una bola de nieve comunitaria, que nos debe alertar dado que comienza con una travesura verbal infantil, termina a nada de un linchamiento colectivo. Juegan aquí las creencias y los prejuicios de la directora y las compañeras de trabajo, un diagnóstico psicológico inducido y mal aplicado con resultado sabido de antemano, las presiones de las diversas familias, la novia del maestro que duda, los vecinos y servidores de la comunidad que se suman ciegamente a la visión dominante, etc. Lo anterior ante el desconcierto, la parálisis y depresión del profesor y de los pocos cercanos leales que quedan.

\subsection{De las instituciones totales al sometimiento total}

Marian es un pequeño niño que es arrebatando a sus padres para internarlo. Es la Checoslovaquia de la década de los años setenta, en la que el Estado se hacía cargo de los 
niños en forma absoluta, dotándolos de los mínimos necesarios: vivienda, alimentación, vestuarios, etcétera.

En este filme presenciamos la evolución de Marian dentro de la institución. Ésta es una especie de reformatorio casa-hogar. Hay niños de varias edades. Asisten a clases con una celadora-maestra: toman dictado, leen, son calificados. Les mandan mensajes grabados del Ministro de Educación fuera de su contexto: "Hoy es el primer día de clases, todavía estará recordando las vacaciones, etcétera”.

El ambiente es terriblemente represivo, los niños son castigados en diversas formas: encerrados en cuartos, descalificados y golpeados. Son nulas las muestras de cariño de los camaradas maestros a los chicos. Entre ellos existen robos y abusos de todo tipo. La mayoría fuma y no les agrada la escuela. Algunos hasta hacen conjuros para que se muera la maestra.

Sin embargo, en un destello, la maestra tiene un acercamiento con Marian. Éste comienza a sentir confianza, con ella, pero dura poco. Al presentarse un conflicto en la enfermería, la maestra le da la razón a una enfermera y quebranta para siempre la incipiente relación. La forma en que está organizada esta escuela es la que algunos teóricos (Goffman, I998) nombran como Institución total: son lugares de residencia y trabajo, donde un gran número de individuos en igual situación, aislados de la sociedad por un período apreciable de tiempo, comparten en su encierro una rutina diaria, administrada formalmente.

En la película queda claro que no son lo suficientemente hospitalarios para que los niños lleguen a educarse. Sin embargo, aprenden a robarse la comida (para comer bien un día por lo menos), aprovecharse de los pequeños, someterse siempre con resistencia a las reglas, a combatir cotidianamente. La gran enseñanza es el resentimiento y la venganza. El mundo claustrofóbico es hostil y la venganza es una forma de supervivencia.

Nuestro joven protagonista llevará siempre las cicatrices generadas por la institución: intentará suicidarse, estará decidido a ser un inadaptado permanente, no tendrá estabilidad emocional, se fugará muchas veces.

En la calle será un delincuente permanente. No está en condiciones de incorporación a una sociedad que lo encerró y lo marcó.

La prisión y la escuela (prisión dentro de la prisión en el film) serán el hogar espeluznante al que Marian siempre tendrá que regresar. La celda representa el eterno retorno al que estará condenado. Es la raíz del tronco torcido en que ha quedado convertido ya de adulto.

Marian (Vaclav, I996: Checoslovaquia) no es una película sobre la escuela, es una desgarradora historia de la no-posibilidad del ser en una situación social adversa, de la importancia del entorno como sello imborrable en el alma: recuerda algunos momentos memorables de Los olvidados (Buñuel, I950) por esos niños a la deriva y sin ruta, así como la vida infernal 
en prisión (El Apando, Papillon, Brubaker, Expreso de Media Noche, Sueños de Fuga, etc.).Pero también demuestra la efectividad del cine checoslovaco para tocar temas humanos (Trenes rigurosamente vigilados, La insoportable levedad del ser, Kolya, etcétera).

\subsection{Otras formas de institucionalización de violencia en la socialización El Señor de las moscas}

La película inicia con un avión que cae en el mar. A bordo viajaba un grupo de niños de escuela militarizada. Los que sobrevivieron llegaron a una isla desierta, ahí comenzaron entre juegos y satisfacción de necesidades, a constituirse como una sociedad. Dos líderes con valores opuestos tratarán de lograr la subsistencia del grupo, venciendo el proyecto más fuerte, que no el más racional o coherente.

Esta película, Lord on the flies (Hook, 1995) basada en la novela de Sir William Golding usa el espacio de una isla tropical, en un largo período en que los niños están dejados a su arbitrio, donde las consecuencias pueden ser funestas, máxime cuando se trata de seres sin contacto social.

Berger y Luckaman (1998) señalan que por lo menos existen dos períodos de socialización: en la primera el niño se inserta a la sociedad por medio de un proceso de aprendizaje cultural. La socialización secundaria es un proceso posterior que induce al individuo socializado a nuevos sectores del mundo objetivo, aceptando roles y otros significantes.

Los escolares del filme tienen entre io y I4 años, de ahí pasan por esta segunda etapa de socialización. La estructura de conocimiento posee una buena cantidad de información para enfrentar la adversa situación: saben de la necesidad de agua, del peligro de algunas especies frutales, de no comer animales en descomposición, de cómo hacer fuego usando cristales, del cuidado a los enfermos, de mantener fuego como posibilidad de ser rescatados.

Pero en esta edad se manifiestan los caracteres y quedan al descubierto los liderazgos. En el relato o descripción de cualquier grupo humano es inevitable dar cuenta de estas guías.

Ralph, desde la llegada a la isla, es el primero en tomar decisiones; él sintetiza las inquietudes y les da cauce. Conforma una asamblea donde su liderazgo es asumido, propone hacer reglas mínimas, coordina esfuerzos hacia la cohesión del grupo, consolida un campamento y estructura con una cierta disciplina el trabajo colectivo en forma flexible. Piggy será pieza clave en este arranque, es por mucho el mejor dotado en conocimientos generales, pero limitado físicamente por ser obeso y miope.

El grupo articulado enfrentará la naturaleza con fortuna, sin embargo, será incapaz de sobrevivir a sí mismo. Jack, que al principio se manifiesta colaborador, pronto asumirá un liderazgo paralelo: primero en un subgrupo de cazadores para después enfrentar abierta- 
mente a Ralph, criticando lo que llamaba excesos disciplinarios. Divide al grupo y es seguido por los de mayor edad, crea rituales, genera miedos y comienza a manifestarse intolerante y salvaje. La violencia social aparece también en este grupo de niños aislados del mundo.

\section{LA VIOLENCIA SOBRE LOS RECURSOS NATURALES}

En otros trabajos (Meixuerio y Ramírez, 2012, 2015 y 20I9) hemos evidenciado cómo el documental y el cine de ficción con temas ambiental se ha vuelto crítico y militante en los últimos tiempos para mostrar cómo el estilo de desarrollo hegemónico en el planeta (industrializador, consumista, individualista, urbano, generador de desechos, tecnologizado, etc.) ejerce una violencia y presión real sobre la base natural de la vida en el mundo, rebasando la capacidad de carga de los ecosistemas en su conjunto. Esto ha provocado una crisis ambiental.

Al respecto, distinguimos dos tipos de documentales centrados en hacer visibles los síntomas de la crisis planetaria ambiental (pérdida de biodiversidad, cambio climático, dominio de la racionalidad económico-industrial, pobreza e impactos ambientales, riqueza y despilfarro de la naturaleza, entre otros). Se evidencia en imágenes y argumentos en forma explícita la relación de la crisis ambiental con la crisis de la civilización y el estilo de desarrollo insustentable.

Los elementos importantes que se observan en este tipo de películas son: producción y consumo de bienes y energía, impacto del desarrollo en el futuro natural, lógica del crecimiento y su transformación de la naturaleza. Ejemplo de este tipo de cine: La corporación (2003), La pesadilla de Darwin (2004), Una verdad incómoda (2006), ¿Quién mató al carro eléctrico? (2006), La última bora (2007), Planeta tierra: informe final (2007), Comprar, tirar, comprar (2011), Food Inc. (2008) y The Cove (2009).

Los temas que se desprenden de este tipo de películas y que se vinculan con la violencia hacia la naturaleza son: razones y significado de la crisis civilizatoria o cambio de era, el papel de la ciencia y la tecnología en la referida crisis, las manifestaciones de la crisis globalizada actual, los valores de la modernidad, las características centrales del proyecto civilizatorio de Occidente, las alternativas y soluciones a los problemas actuales, el papel de la política y la economía en la búsqueda de salidas, la importancia de la sociedad civil o de la ciudadanía, entre otros posibles.

El otro tipo de películas que van más lejos en esta denuncia retratan un mundo catastrófico o apocalíptico, ya sin remedio por la acción de un tipo de violencia extrema. Se trata de películas cuyo contenido aborda las probables consecuencias de la no atención a los 
llamados síntomas de la crisis ambiental (sobreproducción, guerra nuclear, exceso de población, clonación, cambio climático, inundación, etc.). Es un mundo poscatástrofe natural o producto de la agudización de los conflictos sociales, aunque muchas veces poco claros. Son películas con prospectiva negativa: sobre un futuro agravado a partir de las tendencias actuales en donde la violencia es aún peor que en la circunstancia actual.

Lo que hay que seguir en la trama e identificar son las condiciones de vida actual en el marco de los elementos o contextos catastróficos que proponen las películas. Ejemplos de estas son: Blade Runner (1982), Hijos del bombre (2006), Cuando el destino nos alcance (1972), La carretera (2009), El día después de mañana (2004), En la luna (2009), Prometeo (2012), Oblivion (2013) y Elysium (2013).

Estos filmes tienen tal riqueza que nos pueden ayudar a reflexionar sobre la violencia y alrededor de temas como: el futuro como pesadilla humana, el medio ambiente en la ciencia ficción, los distintos mundos posibles a partir de las tendencias actuales, el papel y los fundamentos de la esperanza, las virtudes, la tecnología o atributos con que cuenta la humanidad para construir el futuro después de una hecatombe planetaria, entre varias opciones posibles.

CINE Y VIOLENCIA: GÉNEROS, INTRAFAMILIAR, EN INSTITUCIONES

Y ORGANIZACIONES SOCIALES Y CONTRA LOS RECURSOS NATURALES (CUADRO RESUMEN DE EJEMPLOS)

\begin{tabular}{|c|c|c|c|}
\hline $\begin{array}{l}\text { 1. LA VIOLENCIA } \\
\text { ASOCIADA A GÉNEROS } \\
\text { CINEMATOGRÁFICOS }\end{array}$ & $\begin{array}{l}\text { 2. LA VIOLENCIA } \\
\text { INTRAFAMILIAR EN } \\
\text { EL CINE }\end{array}$ & $\begin{array}{c}\text { 3. CINE DE } \\
\text { INSTITUCIONES } \\
\text { SOCIALES Y VIOLENCIA }\end{array}$ & $\begin{array}{l}\text { 4. CINE DE VIOLENCIA } \\
\text { CONTRA LOS RECURSOS } \\
\text { NATURALES }\end{array}$ \\
\hline $\begin{array}{l}\text { Cine de terror } \\
\text { Sicosis }(1960) \\
\text { El resplandor }(1980) \\
\text { Eso }(1990)\end{array}$ & & & \\
\hline $\begin{array}{l}\text { Cine bélico } \\
\text { Johnny cogió su fusil(1971) } \\
\text { Apocalipsis Now (1979) } \\
\text { Ven y mira (1985) } \\
\text { El hombre de la guerra } \\
\text { (2005) } \\
\text { Minas (2016) }\end{array}$ & $\begin{array}{l}\text { 2.1 Violencia del } \\
\text { hombre a la mujer } \\
\text { Te doy mis ojos (2003) } \\
\text { Retrato de una mujer } \\
\text { casada (1979) }\end{array}$ & $\begin{array}{l}\text { 3.1 La violencia es una } \\
\text { enfermedad mental } \\
\text { Atrapado sin salida } \\
\text { (1975) } \\
\text { Vida de familia (1971) } \\
\text { El paciente interno } \\
\text { (2012) }\end{array}$ & $\begin{array}{l}\text { 4.1 Naturaleza } \\
\text { Planeta tierra (2007) } \\
\text { Chimpancés (2012) }\end{array}$ \\
\hline
\end{tabular}




\begin{tabular}{|c|c|c|c|}
\hline $\begin{array}{l}\text { 1. LA VIOLENCIA } \\
\text { ASOCIADA A GÉNEROS } \\
\text { CINEMATOGRÁFICOS }\end{array}$ & $\begin{array}{l}\text { 2. LA VIOLENCIA } \\
\text { INTRAFAMILIAR EN } \\
\text { EL CINE }\end{array}$ & $\begin{array}{c}\text { 3. CINE DE } \\
\text { INSTITUCIONES } \\
\text { SOCIALES Y VIOLENCIA }\end{array}$ & $\begin{array}{l}\text { 4. CINE DE VIOLENCIA } \\
\text { CONTRA LOS RECURSOS } \\
\text { NATURALES }\end{array}$ \\
\hline $\begin{array}{l}\text { Cine drama o trágico } \\
\text { Hotel Rwanda (2004) } \\
\text { La vida secreta de las } \\
\text { palabras (2005) } \\
\text { El secreto de tus ojos (2009) }\end{array}$ & $\begin{array}{l}2.2 \text { Violencia del } \\
\text { padrastro al hijo } \\
\text { El silencio de Oliver } \\
\text { (1997) } \\
\text { Vida de este chico } \\
\text { (1993) }\end{array}$ & $\begin{array}{l}\text { 3.2 La violencia no se } \\
\text { cura con la violencia } \\
\text { Los hijos de la calle } \\
\text { (1996) } \\
\text { Tropa de élite (2007) }\end{array}$ & $\begin{array}{l}\text { 4.2 Hombre-naturaleza } \\
\text { La guerra del fuego (1981) } \\
\text { Nanuk (1922) } \\
\text { Hombres de Arán (1934) }\end{array}$ \\
\hline $\begin{array}{l}\text { Cine de acción } \\
\text { Operación Dragón (1973) } \\
\text { Rápido y furioso (2001- } \\
\text { 2014) } \\
\text { Contacto en Francia (1971) } \\
\text { En la línea de fuego(1993) }\end{array}$ & $\begin{array}{l}2.3 \text { Violencia } \\
\text { entre hermanas o } \\
\text { hermanos } \\
\text { El matrimonio de } \\
\text { Rache/(2008) } \\
\text { Malena es nombre de } \\
\text { tango (1996) } \\
\text { Amores perros (1999) }\end{array}$ & $\begin{array}{l}\text { 3.3 La violencia como } \\
\text { mentira o juego } \\
\text { La caza (2012) } \\
\text { Fe, esperanza y caridad } \\
\text { (1974) }\end{array}$ & $\begin{array}{l}\text { 4.3 Sociedad-naturaleza } \\
\text { Paisaje transformado } \\
\text { (2006) } \\
\text { Baraka (1992) } \\
\text { La mina del diablo (2008) } \\
\text { Terremoto }(2015) \\
\text { El ardor }(2014)\end{array}$ \\
\hline $\begin{array}{l}\text { Biográfico e histórico } \\
\text { La caída (2004) } \\
\text { Garage Olimpo (1999) } \\
\text { Barry Lyndon (1975) }\end{array}$ & $\begin{array}{l}2.4 \text { Violencia del } \\
\text { hijo a la familia o la } \\
\text { comunidad } \\
\text { Tenemos que hablar } \\
\text { de Kevin (2011) } \\
\text { Elefante }(2003) \\
\text { Niño bonito }(2010)\end{array}$ & $\begin{array}{l}\text { 3.4 De las } \\
\text { instituciones totales } \\
\text { al sometimiento total } \\
\text { Expreso de media noche } \\
\text { (1978) } \\
\text { Sueños de fuga (1994) } \\
\text { La noche de los } 12 \text { años } \\
\text { (2018) }\end{array}$ & $\begin{array}{l}\text { 4.4 Estilo de desarrollo } \\
\text { La historia de las cosas } \\
\text { (2007) } \\
\text { Roger y yo (1989) } \\
\text { La corporación (2003) }\end{array}$ \\
\hline $\begin{array}{l}\text { Western } \\
\text { Un hombre llamado caballo } \\
\text { (1970) } \\
\text { El bueno, el malo y el feo } \\
\text { (1966) }\end{array}$ & & & $\begin{array}{l}\text { 4.5 Crisis ambiental } \\
\text { Enron: Los tipos que } \\
\text { estafaron a América (2006) } \\
\text { La última hora (2007) } \\
\text { La verdad incómoda (2006) } \\
\text { La secuela incómoda } \\
\text { (2017) }\end{array}$ \\
\hline $\begin{array}{l}\text { Walle-eCiencia ficción } \\
\text { Blade Runner(1982) } \\
\text { Terminator(1984-2015) }\end{array}$ & & & $\begin{array}{l}\text { 4.6 La tierra y la especie } \\
\text { humana después de la } \\
\text { Apocalipsis } \\
\text { Mad Max (2015) } \\
\text { La carretera (2009) } \\
\text { Oblivión (2013) }\end{array}$ \\
\hline
\end{tabular}




\begin{tabular}{|l|l|l|l|}
\hline \multicolumn{1}{|c|}{$\begin{array}{c}\text { 1. LA VIOLENCIA } \\
\text { ASOCIADA A GÉNEROS } \\
\text { CINEMTOGRÁfICOS }\end{array}$} & $\begin{array}{c}\text { 2. LA VIOLENCIA } \\
\text { INTRAFAMILIAR EN } \\
\text { EL CINE }\end{array}$ & $\begin{array}{c}\text { 3. CINE DE } \\
\text { INSTITUCIONES } \\
\text { SOCIALES Y VIOLENCIA }\end{array}$ & $\begin{array}{l}\text { 4. CINE DE VIOLENCIA } \\
\text { CONTRA LOS RECURSOS } \\
\text { NATURALES }\end{array}$ \\
\hline $\begin{array}{l}\text { Cine de autor } \\
\text { Naranja mecánica(1971) } \\
\text { Sin City(2005) } \\
\text { Pulp Fiction(1994) } \\
\text { La casa de Jack(2018) } \\
\text { Simplemente sangre(1984) }\end{array}$ & & $\begin{array}{l}\text { 4.7 El cine de } \\
\text { sustentabilidad } \\
\text { La sal de la tierra (2014) } \\
\text { La abuela grillo (2009) } \\
\text { El niño y el mundo (2014) } \\
\text { Wall-e (2008) } \\
\text { Mañana (2015) }\end{array}$ \\
\hline
\end{tabular}

FUENTE: ELABORACIÓN PROPIA (2017).

REFLEXIONES FINALES

Lo contrario a la inseguridad no es la seguridad, sino la convivencia.

GABRIEL TODD

El cine nos ha enseñado que la violencia es la voluntad de rebasar los límites físicos, éticos, económicos y psicológicos, de tolerancia, respeto y derechos de otros seres humanos (y otras especies vivas) contra su voluntad. Es lamentablemente un síntoma generalizado en el malestar civilizatorio actual.

La disminución y contención de la violencia es una tarea impostergable de ser resuelta, por lo que hay que pensar, discutir e indagar mucho sobre ella. En el cine la violencia está presente en la mayoría de los géneros cinematográficos. Lo que podría ser algo positivo si se hace de la experiencia cinematográfica una acción de pensamiento y reflexión, dado que el cine, como arte, imita e influye, simultáneamente en la realidad. Tenemos un cine cada vez más descarnadamente violento. Pero también una sociedad con una recepción más crítica de lo que ve y escucha. Se debe repensar al cine desde su preproducción hasta su recepción crítica evidenciando los significados violentos y no diluyéndolos como algo natural en las tramas.

El cine ha retratado en forma múltiple la violencia. A veces como odas a la guerra o sobrevalorando la acción como sinónimo de un cine donde pasan muchas cosas. La acción en el cine con relativa frecuencia sustituye la reflexión. Como decía el mismo Camus en este género la vida anticipa al pensamiento. 
Sin embargo, el cine también ha denunciado la violencia en lo intrafamiliar, lo ambiental y lo institucional. La violencia es reflejo de lo deshumano y de la pérdida de la dignidad de la persona, de la imposición de fuerza sobre la naturaleza o el prójimo.

La violencia como un hecho socialmente dañino marca para siempre lo mismo sociedades que individuos. La violencia es la fatal evidencia - y lo retrata el cine contemporáneode una especie humana que todavía no se pone de acuerdo con sus intereses y consigo misma. La violencia sigue siendo tan condenable como inevitable ante una convivencia, que evita los sistemas individualistas y superficiales actuales.

\section{REFERENCIAS}

Benítez, N., Meixueiro, A., Ramírez, R. T., \& De la Garza, G. (20II). Los niños y la guerra en el cine contemporáneo mundial: Who'll stop the rain? Revista Electrónica Educativa Pálido.deluz, pp. 2-7. Recuperado el I7 de junio de 2019, de http://palido.deluz.mx/articulos/207

Berger, P., \& Luckmann, T. (1998). La construcción social de la realidad. Buenos Aires, Argentina: Amorrortu.

Careaga, G. (198I). Erotismo, violencia y política en el cine. México: Cuadernos de Joaquín Mortiz.

García Márquez, G. (1986). El cataclismo de Damocles. Bogotá, Colombia: Oveja Negra.

Goffman, E. (1998). Internados. Buenos Aires, Argentina: Amorrortu.

Jiménez, F. (2OI2). Conocer para comprender la violencia: origen, causas y realidad. México: UAEM. Revista Convergencia, 19(58).

Meixueiro, A., \& Ramirez, T. (Coord.) (1998). La vida es mejor que la escuela. México: Sociedad Cooperativa Taller Abierto.

Meixueiro, A., \& Ramírez, T. (2000). Maestra vida. México: Sociedad Cooperativa Taller Abierto, Centro de Estudios Superiores en Educación, Universidad Pedagógica Nacional.

Mexueiro, A., \& Ramírez, T. (2003). Globalización, cine y educación. México: Sociedad Cooperativa Taller Abierto.

Meixueiro, A., \& Ramírez, T. (2012). Mentes peligrosas. Sujetos, miradas y contenidos de educación en películas del siglo XXI. México: Caminos Abiertos.

Moscovici, S. (198I). On social representation. En J.P. Forgas (Comp.). Social cognition. Perspectives in everyday life. Academic Press. Londres: Academic Press.

Ramírez, T. (2009). Manual de Cine y ética para el siglo XXI. Estos ojos y esta palabra también son míos. México: Universidad Anáhuac, Cineteca Nacional, Universidad Pedagógica o95 y Universidad de la Sustentabilidad.

Ramírez, T., \& Meixueiro, A. (2015). Cine y educación ambiental. México: Universidad Pedagógica Nacional, Zonámbula, Pálido.deluz. 
Ramírez, T., \& Meixueiro, A. (2019). Cine, sustentabilidad y educación ambiental. Las articulaciones posibles. México: Universidad Pedagógica Nacional, Zonámbula, Pálido.deluz.

Reigota, M. (2002). Meio Ambiente e Representação Social. São Paulo: Cortez Editora.

Sivard, R. (2010). El planeta en la encrucijada: gastos militares, sociales y crisis ecológica. Barcelona, España: CIP/ICARIA.

Solorzano, F. (2019). Misterios de la sala obscura. Ensayos sobre el cine y su tiempo. México: Taurus. 